\title{
Improving the performance of magnesium alloys for automotive applications
}

\author{
R. O. Hussein \& D. O. Northwood \\ Department of Mechanical, Automotive and Materials Engineering, \\ University of Windsor, Canada
}

\begin{abstract}
Magnesium and its alloys are attractive to the automotive industry for their inherent light-weight which leads to highly fuel-efficient design. However, due to a low melting temperature $\left(650^{\circ} \mathrm{C}\right)$, magnesium has relatively poor elevated temperature mechanical properties, e.g., creep. This has, therefore, restricted its use in applications such as engine components. Magnesium is also a highly reactive metal and has inherently poor corrosion and wear resistance. Improved corrosion and wear performance can be obtained through alloying and microstructural engineering. However, for enhanced corrosion and tribological properties, the use of surface engineering techniques involving coatings is mandatory. Plasma Electrolytic Oxidation (PEO), also known as "Micro-Arc Oxidation (MAO)", has been used to successfully produce oxide layers on magnesium alloys with excellent tribological and corrosion resistant properties. By controlling the PEO process parameters, uniform, relatively pore-free and well adhered coatings can be produced which can provide adequate corrosion protection. The coating requirements for good tribological properties are somewhat different than for good corrosion performance. However, good tribological performance combined with good corrosion performance can be obtained through control of the PEO processing parameters.

Keywords: magnesium alloy, automotive applications, creep, corrosion, wear, PEO coatings.
\end{abstract}

\section{Introduction}

Magnesium is the lightest of all the engineering metals, being 35\% lighter than aluminum and over four times lighter than steel [1]. It is also the eighth most 
abundant element [1]. The low density and ready availability are not the only advantages of magnesium alloys. As noted by Mordike and Ebert [2] in their seminal paper on "Magnesium-properties-applications-potential" other advantages include:

- $\quad$ high specific strength (related to low density);

- $\quad$ good castability (particularly for high pressure die casting);

- can be turned/milled at high speed;

- $\quad$ good weldability;

- $\quad$ improved corrosion resistance (using high purity magnesium).

Mordike and Ebert [2] also emphasize a number of advantages of magnesium alloys over polymeric materials, a major competitor to magnesium alloy in lightweighting applications. These advantages are:

- better mechanical properties;

- resistant to aging;

- better electrical and thermal conductivity;

- recyclable.

Of course, magnesium and its alloys are not without their disadvantages and, again, we can turn to Mordike and Ebert [2] for a succinct summary of these disadvantages which include:

- low elastic modulus;

- limited cold workability and toughness;

- $\quad$ limited strength and creep resistance at elevated temperature;

- $\quad$ high shrinkage on solidification;

- $\quad$ high chemical reactivity with associated poor corrosion resistance.

To this list of disadvantages, we would add inadequate wear resistance.

In this paper we will first take a brief overview of the applications of magnesium and its alloys in the automotive industry. This will be followed by a more detailed overview of efforts to address two of major disadvantages of magnesium alloys, namely limited elevated temperature mechanical properties and poor corrosion resistance. Coatings have found wide usage for corrosion protection of magnesium alloys and we will demonstrate the particular effectiveness of coatings produced by plasma electrolytic oxidation (PEO) which can provide not only corrosion protection but also enhanced wear properties [3].

\section{Application for magnesium and its alloys in the automotive industry}

As noted by Siegel [4], the use of magnesium in automobiles started in the 1920s when it was used in racing cars because of its high strength and light weight. For regular production cars, magnesium was incorporated into the powertrain of the first Volkswagen Beetle in 1936 and reached peak production in 1971 [2, 4]. After that time, automotive applications of magnesium declined due to significant problems including high-temperature creep, flammability, room temperature formability, and corrosion [4]. 
However, alloy development that began in the 1980s has led to increasing use of magnesium in the automotive industry [4]. Since Mordike and Ebert's paper in 2001 [2], there have been a number of review-type papers published on the application of magnesium alloys in the automotive industry [1, 5-10]. The applications can be divided into four major areas, namely: engine and transmission; interior parts; chassis components; body components [1]. One of the major uses of magnesium alloys has been for transmission casings [4]. Magnesium alloys have also found significant application in instrument panels, intake manifolds, cylinder head covers, hood liner sections and steering components [4]. Table 1 provides an overview of the applications, the auto manufacturers that have utilized magnesium, together with selected references for further details. The use of magnesium alloys in these new or higher performance applications required the development of new alloys and fabrication processes $[2,5,7]$.

Table 1: Applications of $\mathrm{Mg}$ alloys in automotive industry. (Adapted from Table 3, ref. [1] with additions and updates.)

\begin{tabular}{|c|c|c|}
\hline Component & Manufacturer(s) & Ref. \\
\hline $\begin{array}{c}\text { Transmission } \\
\text { Casings }\end{array}$ & $\begin{array}{c}\text { Volkswagen Audi, } \\
\text { Mercedes Benz, BMW, Ford, Jaguar, } \\
\text { Daewoo, Volvo, Porsche }\end{array}$ & {$[1,4,8]$} \\
\hline Instrument Panels & $\begin{array}{c}\text { GM, Chrysler, Ford, } \\
\text { Audi, Toyota, Hyundai, Honda }\end{array}$ & $\begin{array}{c}{[2,4,6,7,} \\
10]\end{array}$ \\
\hline $\begin{array}{c}\text { Cylinder Head } \\
\text { Cover }\end{array}$ & $\begin{array}{c}\text { Dodge, Honda, } \\
\text { Alfa Romeo, Daewoo, BMW, Ford, } \\
\text { Isuzu, Volvo, Hyundai, Kia }\end{array}$ & {$[1,4]$} \\
\hline $\begin{array}{c}\text { Steering } \\
\text { Components }\end{array}$ & $\begin{array}{c}\text { Ford, Chrysler, Toyota, BMW, } \\
\text { Lexus, GM, Hyundai, Kia }\end{array}$ & {$[1,2,4,6,7]$} \\
\hline $\begin{array}{c}\text { Seat Frame and } \\
\text { Other Components }\end{array}$ & $\begin{array}{c}\text { GM, Mercedes Benz } \\
\text { Lexus, Hyundai, Kia }\end{array}$ & {$[1,2,6,7,8]$} \\
\hline Engine Block & BMW & {$[1,10]$} \\
\hline Wheels/Rims & GM, Toyota, Alfa Romeo, Porsche & {$[1,10]$} \\
\hline
\end{tabular}

\section{Improving properties/performance}

There seems to be general agreement that magnesium alloys have two major disadvantages with respect to their use in automotive applications, namely a low high temperature (creep) strength and relatively poor corrosion resistance [11]. The low high temperature strength limits the use of magnesium alloys for power train applications such as transmission cases (temperature up to $\sim 170^{\circ} \mathrm{C}$ ), engine blocks $\left(250^{\circ} \mathrm{C}\right)$ and pistons $\left(\sim 300^{\circ} \mathrm{C}\right)[11,12]$. As will be briefly described in section 3.1, new alloys have been developed to extend the application of magnesium alloys to higher temperature applications. However, as described in section 3.2, this improvement in creep strength is obtained through producing 
microstructures that are inherently less corrosion-resistant than the alloys that were less creep-resistant [13].

\subsection{High temperature mechanical properties}

Since magnesium melts at $650^{\circ} \mathrm{C}$, it is obvious that there will be problems in preventing creep in stressed components [2]. For these elevated temperature applications, alloys have been developed with $\mathrm{Ca}, \mathrm{Sr}$, or rare-earth additions [2, $4,10-12,14]$. Many of these "new" alloys were developed from a base of a MgAl alloy, including AE42 and AE44 (rare-earth addition), AJ62 (Sr-addition) and MR1 153M and 230D (Ca+Sr additions) [6].

It is illustrative to look at our own work on the development of the AC51 $(\mathrm{Mg}-5.0 \mathrm{Al}-1.0 \mathrm{Ca})$ and AC52 $(\mathrm{Mg}-0.5 \mathrm{Al}-2.0 \mathrm{Ca})$ alloys from an AM50 (Mg5.0Al-0.3Mn) base alloy [12]. The coarse, discontinuous $\mathrm{Mg}_{17} \mathrm{Al}_{12}$ phase in the AM50 alloy was gradually replaced by fine $(\mathrm{Al}, \mathrm{Mg})_{2} \mathrm{Ca}$ eutectic phases as the $\mathrm{Ca}$ content increased and there was a general refinement of the as-cast microstructure. The $(\mathrm{Al}, \mathrm{Mg})_{2} \mathrm{Ca}$ phase is thermally more stable at higher temperatures which contributes to a higher creep resistance. The $(\mathrm{Al}, \mathrm{Mg})_{2} \mathrm{Ca}$ phase is present as step-shaped particles along the grain boundaries in the AC51 and AC52 alloys which effectively blocks the movement of dislocations and the sliding of grain boundaries, both of which provide increased creep resistance [12]. There are also solid solution hardening effects of the $\mathrm{Ca}$ addition to the alloys.

\subsection{Corrosion resistance}

Magnesium has a high chemical reactivity and, therefore, an inherently poor corrosion resistance. One of the major steps in improving the corrosion resistance of magnesium alloys is considered to be the introduction of high purity alloys [11]. The "impurities" includes oxides, nitrides, carbides, chlorides and other non-metallic inclusion resulting from the melting and casting [13] and an array of iron-rich intermetallic compounds formed between $\mathrm{Fe}$ and other alloying elements (Al, Si, rare-earth) elements in the magnesium alloys [13]. These impurities and intermetallic compounds "serve as intense local cathodes, driving anodic dissolution" [15] of the magnesium and hence, reducing the corrosion resistance [16]. This phenomenon has been described as "internal galvanic corrosion' due to its similarity to "regular" galvanic corrosion that occurs if magnesium is in contact with another metal and an electrolyte. This also presents significant challenges to the development of high strength, creep resistance since it is precisely those intermetallics that have produced the high strength and creep resistance.

The idea of "stainless magnesium" is attractive. If we try to mimic the development of stainless steel, where the addition of greater than $12 \% \mathrm{Cr}$ led to the replacement of native (non-protective) oxide with a passive (protective) oxide, we run into a number of "problems". As pointed out by Birbilis et al. [15], most elements have limited solubility in $\mathrm{Mg}$ and therefore it is impossible to reach the critical alloying content to form the passive oxide. Furthermore, any of 
the elements that form oxides in preference to magnesium are even more reactive and less corrosion resistant. However, Birbilis et al. [15] were able to produce "stainless magnesium" through the development of an Mg-3.7wt\%As alloy. Rather than forming a passive oxide, As acts as an inhibitor that retards the cathodic reaction $\left(2 \mathrm{H}_{2} \mathrm{O}+2 \mathrm{e}^{-} \rightarrow \mathrm{H}_{2}+2 \mathrm{OH}^{-}\right)$by inhibiting hydrogen atom recombination. Rather than uniform corrosion, the $\mathrm{Mg}$-As exhibited filiform corrosion in tests $0.1 \mathrm{M} \mathrm{NaCl}$. Also, such an alloy would not have the strength required for structural application. Thus, the main route to corrosion-resistant magnesium alloys would appear to be through the use of coatings [16].

\subsection{Wear}

It is generally recognized that magnesium has poor wear resistance $[11,17]$ and that this is related to a low hardness. Dobrzanski et al. [18] for instance, have shown that the abrasive wear performance of four Mg-alloys for potential use in the automotive industry is related directly to the hardness obtained through heat treatment: a higher hardness providing a better wear resistance, and hence the lowest wear was for alloys subjected to an aging heat treatment [18]. Aging produces internal galvanic corrosion as described in section 3.2. Since wear, like corrosion, is a surface phenomenon, a number of techniques have been developed to produce surface hardening or strengthening [17] but not all techniques can also produce increased corrosion resistance.

The relatively poor wear performance of magnesium and its alloys is also related to magnesium's high reactivity and relatively low melting point. Dry sliding wear tests for AZ91D alloy have shown two wear regimes, mild wear and severe wear [19]. In the mild wear regime, oxidational wear was identified as one of the two micromechanisms [19]. In the severe wear regime, melt wear and severe plastic deformation wear identified as the two main wear micromechanisms [19].

\section{Use of coatings for magnesium alloys}

\subsection{General observations}

A variety of coating methods have been used for magnesium and other light metal (Al, Ti) alloys $[1,3]$. These can be divided into three general categories, namely (i) conversion coatings; (ii) inorganic coatings: and (iii) organic/polymer coatings $[3,16]$ (see Figure 1). In general, the organic/polymer coatings might provide adequate corrosion protection but not the required wear resistance. There has been much attention paid to the "conversion coatings" group, which includes anodizing. Plasma Electrolytic Oxidation (PEO), also called Micro-Arc Oxidation (MAO), has proven particularly useful for coating magnesium. The PEO process can be considered a combination of anodizing (electrolytic oxidation) and plasma discharging processes. PEO can produce harder, more compact oxide coatings than those produced by hard anodizing and these coatings provide superior corrosion and wear resistance to the anodized coatings. 
With respect to the use of PEO coatings on magnesium, there is one particular application that is somewhat different than automotive, and this is PEO-coated magnesium alloys for biodegradable implants [20]. These coatings are designed to delay the rate of corrosion attack during the initial period of implantation but, ultimately, the implant should be biodegradable [20]. Coatings for automotive applications, however, are designed to provide long term corrosion resistance.

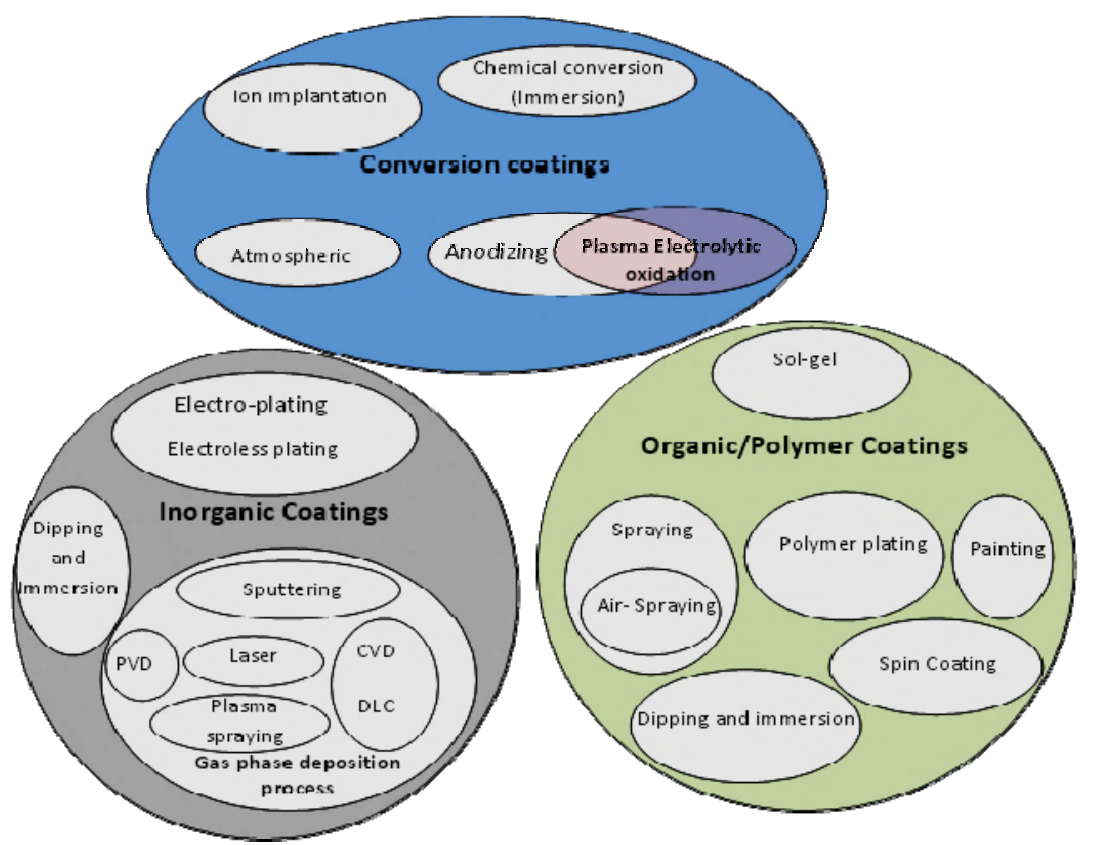

Figure 1: Schematic diagram showing coating technologies for magnesium alloys [3].

\subsection{PEO coatings for magnesium alloys}

The PEO process involves the creation of plasma discharges around a metal component immersed in an environmentally friendly electrolyte. The discharge events have a profound effect on coating microstructure, and hence on the physical and mechanical properties of the coating [21]. During PEO coating, there are three simultaneous processes taking place, namely the electrochemical reactions, the plasma chemical reactions and thermal oxygen diffusion [22].

In general, PEO coatings on $\mathrm{Mg}$ alloys have been found to have a threelayered structure (as shown in Figure 2) for an AM60B alloy. Figure 2(a) is a SEM micrograph of the surface of the coating. Figure 2(b) is a SEM micrograph of a cross-section of the coated alloy. Figure 2(c) is a schematic showing a porous outer layer, an intermediate layer that is relatively dense and a thin inner dense (barrier) layer that is well adhered to the substrate. We will return to this point later but would note that although it is the intermediate dense layer that can 
provide good mechanical properties (e.g. wear) and corrosion protection, it is the inner dense layer that ultimately provides the best corrosion performance [3]. Examination of the surface morphology of the coatings, Figure 2(a), shows pores of different sizes: the size reflecting the strength of the discharges that produced the pores. There are both open and closed pores. The relatively large open pores are concentrated on the surface of the PEO coatings whereas the closed pores are present in the middle region of the coating. The surface of the coatings shows a 'pancake' structure wherein the center of each pancake was a discharge channel through which the molten magnesium surged out of the channel and is quickly solidified by the relatively cool electrolyte, leaving distinct boundaries that define each pancake. The uneven melting and sintering effect causes the formation of a rough surface which could adversely affect the wear performance through an increase in the coefficient of friction (COF). The channels at the center of the pancake can penetrate as far as the substrate surface which will degrade the overall corrosion resistance. Thus, in producing PEO coatings, the elimination, or at least minimization, of such structure is of primary concern.

Although, in general, PEO coating of $\mathrm{Mg}$ alloys produces the three-layered structure (shown in Figure 2), the relative proportions of the three-layers, their thicknesses, microstructure, porosity, phase content and composition are strongly influenced by the substrate composition, electrolyte composition and concentration and the PEO process parameters, including current density, current mode, applied voltage, frequency and duty cycle $\left(\mathrm{t}_{\mathrm{on}} /\left(\mathrm{t}_{\mathrm{on}}+\mathrm{t}_{\mathrm{off}}\right)\right)$, and treatment time [3].

The electrolyte chemistry (concentration and composition) is an important parameter affecting the PEO discharge characteristics and breakdown voltage, and thereby microstructure, porosity, and thickness of the PEO coatings. The PEO base electrolyte is $\mathrm{KOH} / \mathrm{NaOH}$ with the addition of the silicate, phosphate, aluminate $[3,23]$ which can cause an increase of electrolyte conductivity and decreases the voltage breakdown. Tungstate, zirconate and permanganate have also been explored as additives in the electrolytes used to prepare PEO coatings on Mg alloys [20]. XRD patterns for PEO coatings on Mg alloys show that the coatings are comprised of amorphous and crystalline phases such as $\mathrm{MgO}$, $\mathrm{Mg}_{2} \mathrm{SiO}_{4}, \mathrm{Mg}_{3}\left(\mathrm{PO}_{4}\right)_{2}$ or $\mathrm{MgAl}_{2} \mathrm{O}_{4}$, depending on the electrolyte [3]. An enrichment of the $\mathrm{MgAl}_{2} \mathrm{O}_{4}$ phase in the coating, together with a minimum amount of cubic $\mathrm{MgO}$, has been shown to improve the corrosion resistance of the coated alloy [3]. $\mathrm{MgAl}_{2} \mathrm{O}_{4}$, which is a spinel phase is also much harder (7.5-8.0 Mohs scale) than $\mathrm{MgO}(6.0-6.5)$ or $\mathrm{Mg}$ (2.5) and can provide better wear resistance.

Increasing the current density and/or voltage leads to an increase in layer thickness, an enlargement of the surface craters and increased porosity and other coating defects. The growth rate, porosity level and microstructure of PEO coatings formed on $\mathrm{Mg}$ alloys are significantly influenced by the current mode. By adjusting the cathodic to anodic current ratio and their timing $\left(\mathrm{T}_{\text {on }}\right.$ and $\left.\mathrm{T}_{\text {off }}\right)$ the strongest plasma discharges can be eliminated, or at least reduced. Studies on an AJ62 magnesium alloy show that the use of a bipolar current mode results in the formation of dense (minimum porosity and other defects) inner layer coatings 
with minimum outer layer compared to coatings obtained using a unipolar, AC or DC mode [24]. By applying a unipolar current mode, thereby generating strong discharges, the porosity (amount and size) and other defects increase while the outer and inner layer thicknesses also increase [21].
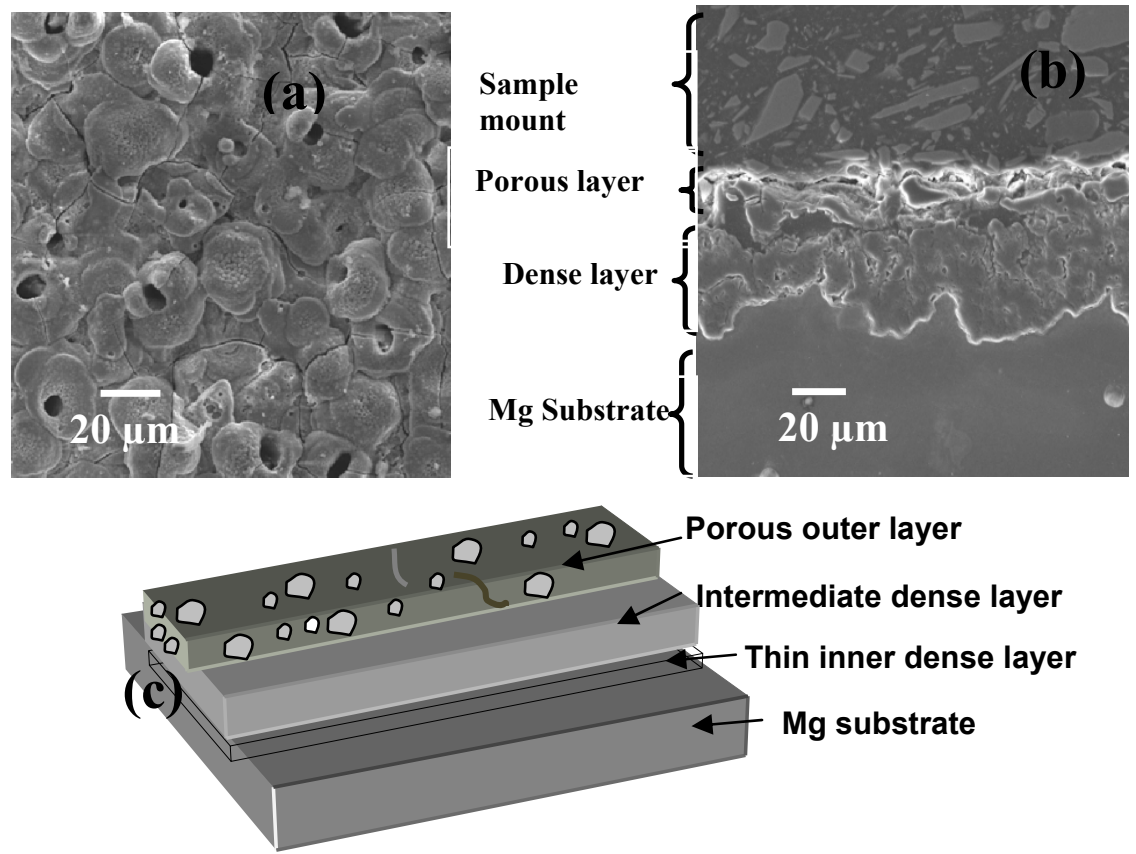

Figure 2: SEM micrographs of PEO coating on AM60B alloy showing (a) the surface morphology and (b) cross-section; (c) general schematic [3].

\subsection{Balancing tribological and corrosion performance}

As noted on section 3.2, the corrosion performance on uncoated magnesium alloys largely depends on the alloying and impurity elements (both amount and chemistry). For PEO-coated materials, there are also effects of the magnesium alloy substrate but the primary enhancement of the corrosion resistance comes from the 3-layer oxide structure shown in Figure 2, particularly the inner, dense barrier layer, but also the relatively dense intermediate layer.

To illustrate the different effects (substrate and coating) on corrosion resistance, we present the results of electrochemical impedance spectroscopy (EIS) corrosion tests in $3.5 \% \mathrm{NaCl}$ solution at $25^{\circ} \mathrm{C}$. Data are presented for pure$\mathrm{Mg}$ and three magnesium alloys (AJ62, AM60B and AZ91D) in the uncoated and PEO-coated conditions. The PEO-coatings were produced using a bipolar current mode which has been shown to produce a denser coating than a unipolar mode [3]. The EIS results, presented in the form of Nyquist plots, are shown in Figure 3 together with the equivalent circuits that were used for fitting and 
analysis of the EIS plots. In the equivalent circuits for uncoated alloys (Figure 3(b)) and PEO-coated alloys (Figure 3(d)) $\mathrm{R}_{\mathrm{S}}$ represent the resistance of the electrolyte; R1 is the coating resistance (virtual pore resistance) which is parallel with a constant phase element CPE1. CPE2 is the constant phase element for the double layer capacitance of the interface electrical double layer at, or near, the coating/substrate interface. R2 represent the polarization resistance which is the Faradic charge transfer resistance related to electrochemical reactions in the same coating/substrate interface region.
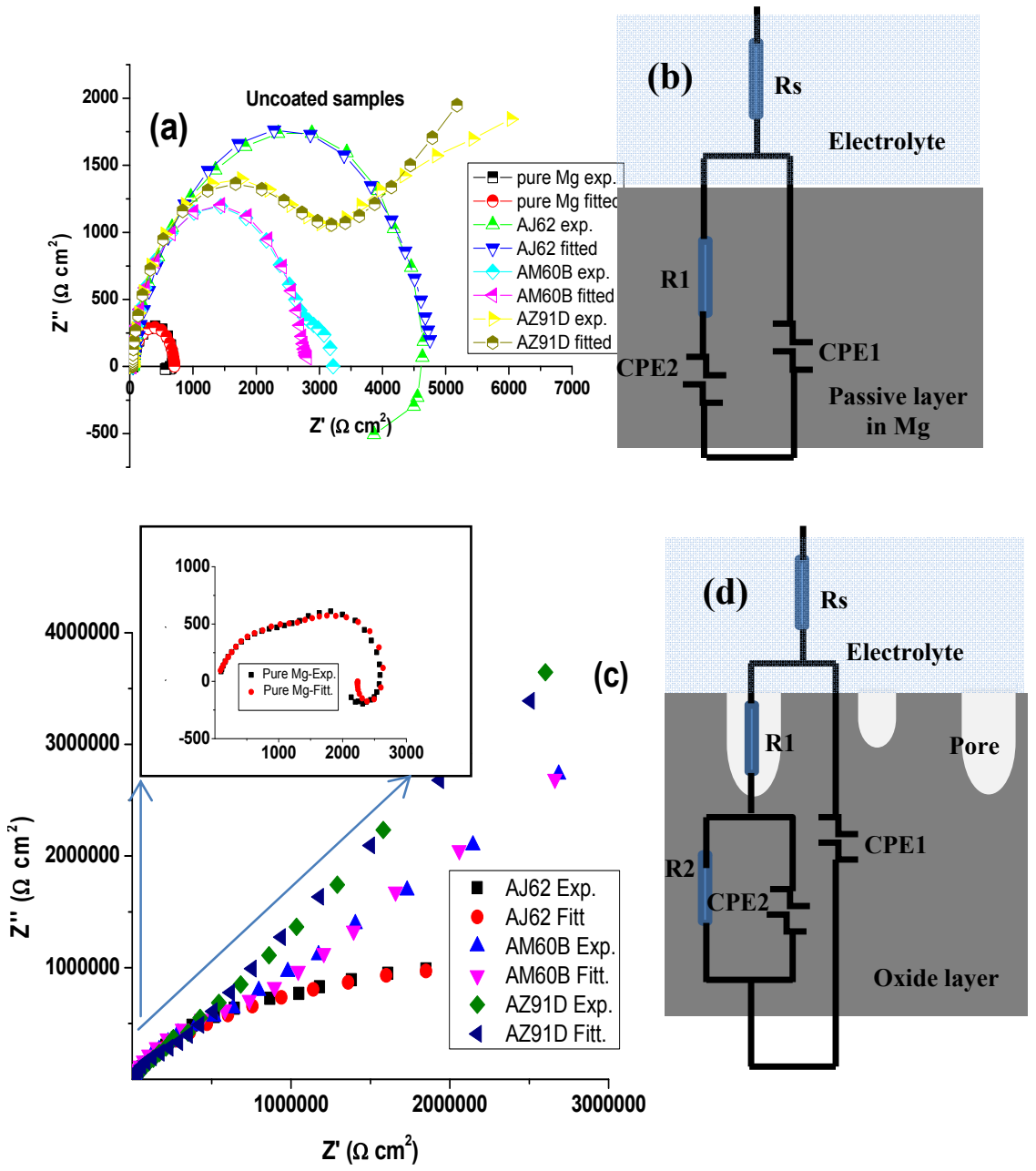

Figure 3: Nyquist plots and equivalent circuits proposed for fitting of EIS plots of (a), (b) uncoated pure $\mathrm{Mg}$ and $\mathrm{Mg}$ alloys and (c), (d) PEO coated samples. 
As can be seen by comparing Figure 3(a) with Figure 3(c) the impedance response of the uncoated $\mathrm{Mg}$ alloys is very different from that of the coated specimens. The differences in impedance are related to the corrosion protection mechanisms for the alloys provided by the naturally formed oxide layer (few $\mathrm{nm}$ ) which is easily corroded by the corrosive electrolyte. Table 2 summarizes all the fitted EIS results for the uncoated samples: the R1 results show the poor corrosion resistance of all uncoated alloys. There are some differences depending on alloy content. The order of increasing corrosion resistance is pure $\mathrm{Mg}<$ AZ91D $<$ AM60B $<$ AJ62.

Table 2: $\quad$ Fitting results of diagrams of uncoated Mg alloys using equivalent circuit Rs+CPE1/(R1+CPE2).

\begin{tabular}{|l|l|l|l|l|l|}
\hline Sample & $\begin{array}{l}\text { CPE1-Q } \\
\left(\mathrm{F} / \mathrm{cm}^{2} \mathrm{~s}^{1-\mathrm{n}}\right)\end{array}$ & CPE1-n & $\begin{array}{l}\text { R1 } \\
\left(\Omega \cdot \mathrm{cm}^{2}\right)\end{array}$ & $\begin{array}{l}\text { CPE2-Q } \\
\left(\mathrm{F} / \mathrm{cm}^{2} \mathrm{~s}^{1-\mathrm{n}}\right)\end{array}$ & CPE2-n \\
\hline Pure $\mathrm{Mg}$ & $6.528 \mathrm{e}-6$ & 0.93 & 650.5 & 0.194 & $8.475 \mathrm{e}-3$ \\
\hline AJ62 & $13.79 \mathrm{e}-6$ & 0.81 & 4748 & 0.049 & $5.812 \mathrm{e}-6$ \\
\hline AM60B & $4.742 \mathrm{e}-6$ & 0.93 & 2632 & $7.283 \mathrm{e}-3$ & 0.1834 \\
\hline AZ91D & $4.823 \mathrm{e}-6$ & 0.95 & 2470 & $0.3596 \mathrm{e}-3$ & 0.3836 \\
\hline
\end{tabular}

The fitted EIS results for the coated materials are given in Table 3. As can be seen by examining R1 and R2 values, the protection afforded by the oxide coating is at least three orders of magnitude higher than that offered by the naturally occurring oxide on the uncoated samples.

Table 3: Fitting results of EIS diagrams of PEO treated $\mathrm{Mg}$ alloys using equivalent circuit $\mathrm{Rs}+\mathrm{CPE} 1 /(\mathrm{R} 1+\mathrm{CPE} 2 / \mathrm{R} 2), \mathrm{Rs}=20 \Omega \bullet \mathrm{cm}^{2}$.

\begin{tabular}{|c|c|c|c|c|c|c|}
\hline Sample & $\begin{array}{c}\text { CPE1-Q } \\
\mu \mathrm{F} / \mathrm{cm}^{2} \mathrm{~s}^{1-\mathrm{n}}\end{array}$ & CPE1-n & $\begin{array}{c}\mathrm{R} 1 \\
\mathrm{M} \Omega \cdot \mathrm{cm}^{2}\end{array}$ & $\begin{array}{c}\text { CPE2-Q } \\
\mu \mathrm{F} / \mathrm{cm}^{2} \mathrm{~s}^{1-\mathrm{n}}\end{array}$ & $\begin{array}{c}\text { CPE2- } \\
\mathrm{n}\end{array}$ & $\begin{array}{c}\mathrm{R} 2 \\
\mathrm{M} \Omega \cdot \mathrm{cm}^{2}\end{array}$ \\
\hline AJ62 & 0.055 & 0.75 & 1.970 & 0.465 & 0.52 & 2.191 \\
\hline AM60B & 0.094 & 0.80 & 1.875 & 0.320 & 0.82 & 8.796 \\
\hline AZ91D & 0.116 & 0.75 & 1.188 & 0.162 & 0.99 & 12.142 \\
\hline
\end{tabular}

A comparison of the coated-uncoated alloys is given in Table 4. The total resistance to corrosion $R_{T}=\sum_{n=2}^{n} R_{n}$ after the PEO treatment is listed in Table 4 together with the protection efficiency (PEF \%) afforded by the coating which has been calculated using the relationship [26]:

$$
P_{E F} \%=100 \times\left[R_{T}^{-1}(\text { uncoated })-R_{T}^{-1}(\text { coated })\right] / R_{T}^{-1}(\text { coated }) .
$$

All PEO-coatings, except on pure-Mg, provide a high level of protection with the coating on AZ91D providing the highest level of protection. The differences 
observed for the three alloys are considered to be related to differences in porosity.

Table 4: The total resistance $\left(\mathrm{R}_{\mathrm{T}}\right)\left(\mathrm{M} \Omega \cdot \mathrm{cm}^{2}\right)$ and protection efficiency (eq. (1)) of the uncoated and PEO coated different (for $30 \mathrm{~min}$ ) Mg-alloys.

\begin{tabular}{|c|c|c|c|c|}
\hline Sample & Pure Mg & AJ62 & AM60B & AZ91D \\
\hline $\mathbf{R}_{\mathbf{T}}$ uncoated & $6.50 \times 10^{-4}$ & $4.75 \times 10^{-3}$ & $2.63 \times 10^{-3}$ & $2.47 \times 10^{-3}$ \\
\hline $\mathbf{R}_{\mathbf{T}}$ coated & $4.71 \times 10^{-3}$ & 4.161 & 10.67 & 13.33 \\
\hline $\mathrm{P}_{\mathrm{EF}} \%$ & 6.24 & 876 & 4134 & 5397 \\
\hline
\end{tabular}

Turning to the tribological properties, it is found that PEO ceramic coatings exhibit a relatively high hardness due to a structural change in the coating's inner region caused by diffusion processes [22]. Usually PEO-coated materials show a higher coefficient of friction (COF), due to high roughness, but a lower wear rate than the uncoated $\mathrm{Mg}$ alloys. It has also been found that the wear resistance increased with increasing coating thickness due to an enhanced load-bearing capability and the increase of the effective adhesion of the oxide layer.

Corrosion and wear studies of a PEO-coated AM60B alloy [25] illustrate how a coating can be formed with both good corrosion and wear properties. PEO-coatings were formed using both unipolar and bipolar current modes. The wear resistance was evaluated using a pin-on-disk set-up under dry conditions and a $2 \mathrm{~N}$ applied load. Test were stopped after reaching a total wear distance of $100 \mathrm{~m}$. Corrosion testing was performed in a $3.5 \mathrm{wt} \% \mathrm{NaCl}$ solution using a potentiodynamic polarization technique. $\mathrm{Rp}$, the polarization resistance, was used as the measure of corrosion resistance. The results are summarized in Table 5 and Figure 5. PEO coating decreases the wear rate (Figure 5(b)), increases the corrosion resistance but also increases the COF. This increase in $\mathrm{COF}$ is related to the increase in surface roughness (Figure 5(a)). Comparison of the PEO-coatings prepared using a bipolar current mode compared to those prepared using a unipolar current mode, show an improvement in both corrosion and wear resistance (including a decrease in COF), even though the coatings were thinner. Use of a bipolar current mode reduces the large discharges and thus number of large pancake features on the surface, thus lowering the surface

Table 5: Characterization of uncoated and coated samples, wear and corrosion results. $\left(\mathrm{T}=\right.$ coating thickness $\mu \mathrm{m}, \mathrm{R}_{\mathrm{Z}}=$ Surface roughness $\mu \mathrm{m}, \mathrm{w}=$ wear rate $\times 10^{-4} \mathrm{~mm}^{3} / \mathrm{N} \mathrm{m}, \mathrm{Rp}=$ polarization resistance $\mathrm{M} \Omega \cdot \mathrm{cm}^{2}$, Ps $=$ Ave. pore sizes $\mu$.

\begin{tabular}{|c|c|c|c|c|c|c|c|}
\hline S & $\mathbf{T}$ & $\mathbf{R z}$ & $\mathbf{P s}$ & $\mathbf{C O F}$ & $\mathbf{W}$ & $\mathbf{R}_{\mathbf{p}}$ & $\mathrm{P}_{\mathrm{EF}} \%$ \\
\hline S0 & NA & $2.6 \pm 0.2$ & NA & $0.4-0.5$ & $9.0 \pm 2.7$ & 0.27 & N/A \\
\hline U & 40 to 55 & $44.3 \pm 1.6$ & 15.0 & $0.7-0.8$ & $6.24 \pm 2.0$ & 58 & 209 \\
\hline B & 31 to 42 & $31.3 \pm 0.7$ & 9.5 & $0.5-0.6$ & $1.78 \pm 0.4$ & 835 & 3015 \\
\hline
\end{tabular}


roughness and COF. The pore size is smaller for bipolar which produces a more corrosion-resistant coating. A denser coating leads to a higher hardness, and better wear performance.
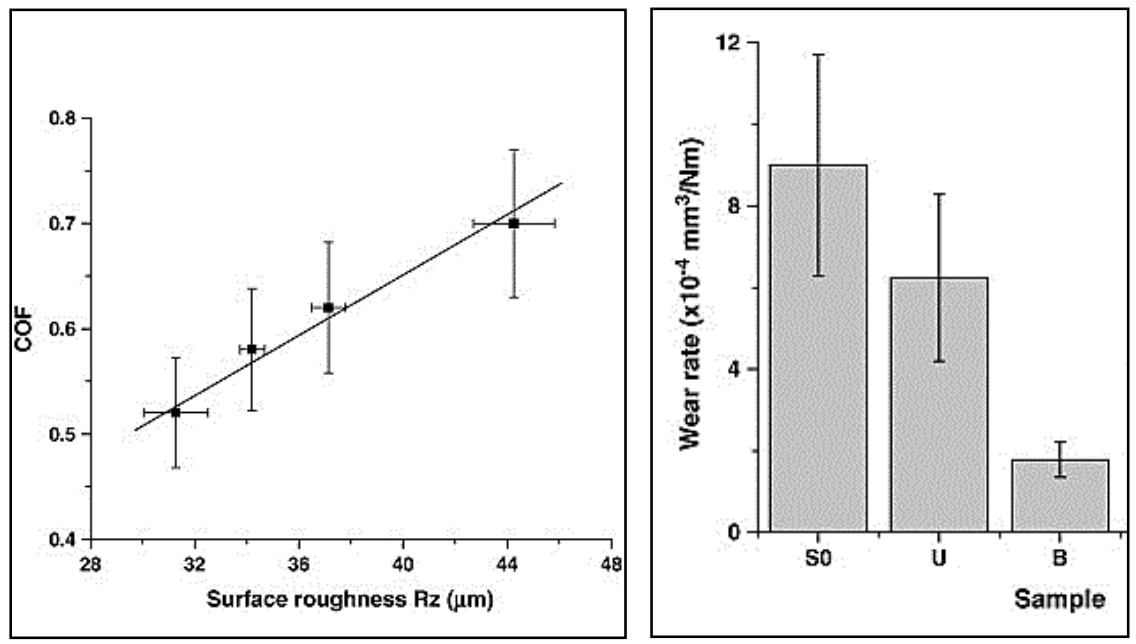

Figure 4: (a) Coefficients of friction vs. roughness parameter Rz of the oxide coatings on AM60B-Mg alloy substrate. (b) Wear rates of the oxide coatings formed using different current modes and the uncoated $\mathrm{Mg}$ alloy substrate (S0).

There are situations where the structure for good corrosion and wear performance are not the same. An example would be for oil-lubricated wear where the presence of a porous outer layer in the PEO coating could act as an oil reservoir, improving wear performance [26].

\section{Concluding remarks}

Magnesium alloys are very attractive for a range of weight-sensitive applications, including automotive. They have found their way into four major areas in the automobile, namely (i) engine and transmission, (ii) interior parts, (iii) chassis components and (iv) body components. The use of Mg-alloys in powertrain components has led to the development of a number of new alloys containing rare-earth, $\mathrm{Sr}$ and $\mathrm{Ca}$ additions that have much improved high temperature mechanical properties.

Because of magnesium's high chemical reactivity, most magnesium alloys demonstrate relatively poor corrosion performance. Impurities and any intermetallic compounds, including those providing improved high temperature mechanical properties, further degrade the corrosion resistance. The main route to more corrosion resistant magnesium alloys has been through the use of coatings. Plasma Electrolytic Oxidation (PEO) has proven to be an attractive 
method of producing such coatings. Through a control of the PEO process parameters, oxide coatings can be produced that offer excellent corrosion protection. These oxide coatings are hard and adherent and also provide the magnesium alloys with much improved tribological properties.

\section{References}

[1] Kulekci, M.K., Magnesium and its alloys applications in automotive industry, International Journal of Advanced Manufacturing Technology, 39, pp. 851-865, 2008.

[2] Mordike, B.L. and Ebert,T. Magnesium properties-applications-potential, Material Science and Engineering, A302, pp. 37-45, 2001.

[3] Hussein, R.O., Nie, X., and Northwood, D.O., The application of Plasma Electrolytic Oxidation (PEO) to the production of corrosion resistant coatings on magnesium alloys: a review, Corrosion \& Materials, 38(1), pp. 54-65, 2013.

[4] Siegel, R.P., Advanced materials for lightweighting cars: stainless magnesium could become a contender. http:news. Thomasnet.com/green clean_2013/09/27/advanced-materials-for lightweighting-cars-stanlessmagnesium-could-become-a-contender/

[5] Easton, M., Beer, A., Barnett, M., Davies, C., Dunlop, G., Durandet, Y., Blacket, S., Hilditch, T. and Beggs, P., Magnesium alloy applications in automotive structures, J0M, 60(11), pp. 57-62, 2008.

[6] Musfirah, A.H. and Jaharah, A.G., Magnesium and aluminium alloys in automotive industry, Journal of Applied Sciences Research, 8(9), pp. 4865-4875, 2012.

[7] Kim, J.J. and Han, D.S., Recent development and applications of magnesium alloys in the Hyundai and Kia Motors Corporation, Materials Transactions, 49(5), pp. 894-897, 2008.

[8] Gandara, M.S.F., Recent growing demand for magnesium in the automotive industry, Materials and Technology, 45(6), pp. 633-637, 2011.

[9] Monteiro, W.A., Buso, S.J. and daSilva, L.V., Applications of magnesium alloys in transport (chapter 7), New Features on Magnesium Alloys, ed. W.A. Monteiro, InTech: Rijeka, Croatia, pp. 1-14, 2012. http://www.intechopen.com/books/new-features-on-magnesium-alloys-intransport

[10] International Magnesium Association, Magnesium in motion, $\mathrm{Mg}$ Showcase, Issue 7, pp. 1-4, January 2009. www.intlmag.org

[11] Key to Metals, Automotive uses of magnesium alloys: part two, pp. 1-3, August 2010. http://www.Keytometals.com/page.aspx?ID=CheckArticle\& amp;site=ktn\&amp;NM=248

[12] Han, L., Hu H. and Northwood, D.O., Development of creep-resistant magnesium casting alloys for high temperature automotive applications, WIT Transactions on The Built Environment, 97, pp. 53-62, 2008. 
[13] Lun Sin, S., Elsayed, A. and Ravindran, C., Inclusions in magnesium and its alloys: a review, International Materials Reviews, 58(7), pp. 419-436, 2013.

[14] Luo, A.A., Recent magnesium alloy development for elevated temperature applications, International Materials Reviews, 49(1), pp. 13-30, 2004.

[15] Birbilis, N., Williams, G. Gusieva, K., Samaniego, A., Gibson, M.A. and McMurray, H.N., Poisoning the corrosion of magnesium, Electrochemistry Communications, 34, pp. 295-298, 2013.

[16] Guo, K.W., A review of magnesium/magnesium alloys corrosion and its protection. Recent Patents on Corrosion Science, 2, pp. 13-21, 2010.

[17] Sun, H.Q., Shi, Y-N. and Zhang, M-X., Wear behaviour of AZ91D magnesium alloy with a nanocrystalline surface layer, Surface \& Coatings Technology, 202, pp. 2859-2864, 2008.

[18] Dobrzanski, L.A., Tanski, T., Cizek, L. and Domagala, J., Mechanical properties and wear resistance of magnesium casting alloys, Journal of Achievements in Materials and Manufacturing Engineering, 31(1), pp. 8390, 2008.

[19] Chen H., Alpas A.T., Sliding wear map for the magnesium alloy Mg-9Al0.9 Zn (AZ91), Wear, 246, pp. 106-116, 2000.

[20] Sankara Narayanan, T.S.N., Park, I.S. and Lee, M.H., Strategies to improve the corrosion resistance of microarc oxidation (MAO) coated magnesium alloys for degradable implants: prospects and challenges, Progress in Material Science, 60, pp. 1-71, 2014.

[21] Hussein RO, Nie X, Northwood DO, Yerokhin A, Matthews A. Spectroscopic study of electrolytic plasma and discharging behaviour during the plasma electrolytic oxidation (PEO) process. Journal of Physics D: Applied Physics, 43, pp. 105203, 2010.

[22] Hussein RO, Nie X, Northwood DO, An investigation of ceramic coating growth mechanisms in plasma electrolytic oxidation (PEO) processing, Electrochimica Acta, 112, pp. 111-119, 2013.

[23] Hussein RO, Northwood DO, Nie X. The influence of pulse timing and current mode on the microstructure and corrosion behaviour of a plasma electrolytic oxidation (PEO) coated AM60B magnesium alloy. Journal of Alloys and Compounds, 541, pp. 41-8, 2012.

[24] Hussein RO, Zhang P, Nie X, Xia Y, Northwood DO. The effect of current mode and discharge type on the corrosion resistance of plasma electrolytic oxidation (PEO) coated magnesium alloy AJ62. Surface \& Coatings Technology, 206: pp. 1990-7, 2011

[25] Hussein R.O., Northwood D.O., Su J.F., Nie X., A study of the interactive effects of hybrid current modes on the tribological properties of a PEO (plasma electrolytic oxidation) coated AM60B Mg-alloy, Surface \& Coatings Technology, 215, pp. 421-430, 2013.

[26] Guo L.J.W., Liang J., Xue Q and Yan F., Tribological behavior of plasma electrolytic oxidation coating on magnesium alloy with oil lubrication at elevated temperatures. Journal of Alloys and Compounds. 481, pp. 903909, 2009. 